\title{
Bajo riesgo de malignidad en pacientes con artritis reumatoidea tratados con terapia biológica
}

Low risk of malignancy in patients with rheumatoid arthritis treated with biologic therapy

\section{Objetivo}

Evaluar el riego de malignidad asociado al tratamiento con terapias biológicas en pacientes con artritis reumatoidea (AR).

\section{Fuentes de datos}

Bases de datos electrónicas (MEDLINE, Cochrane Library, EMBASE), resúmenes de trabajos presentados en congresos europeos y norteamericanos y sitios de Internet de agencias regulatorias.

Selección de estudios y extracción de datos

Fueron incluidos los ensayos clínicos controlados y aleatoriza-

Tabla 1. Comparación entre los diferentes esquemas terapéuticos.

\begin{tabular}{|c|c|c|c|}
\hline & Biológicos & $\begin{array}{l}\text { Biológicos más Metotrexate } \\
\text { (y/o DMAR) }\end{array}$ & Controles \\
\hline Número de pacientes & 3.615 & 15.989 & 9.819 \\
\hline Número de pacientes con malignidad & 23 & 123 & 65 \\
\hline Discontinuación por evento adverso & $23 \%$ & $33 \%$ & $18 \%$ \\
\hline Falta de eficacia & $37 \%$ & $29 \%$ & $50 \%$ \\
\hline $\begin{array}{l}\text { Tasa de incidencia de malignidad durante el primer año de } \\
\text { tratamiento e IC95\% }\end{array}$ & $\begin{array}{c}0,64 \% \\
(0,42 \text { a } 0,95 \%)\end{array}$ & $\begin{array}{c}0,77 \% \\
(0,65 \text { a } 0,92)\end{array}$ & $\begin{array}{c}0,66 \% \\
(0,52 \text { a } 0,84)\end{array}$ \\
\hline
\end{tabular}

Globalmente no hubo diferencias clínicamente relevantes en el riesgo de incidencia de cáncer. Sólo se observó un incremento estadísticamente significativo en la incidencia de cáncer a las 52 semanas a de seguimiento en el grupo anti-TNFa más metotrexate, cuando se lo comparó con el grupo control (peto OR 2,1; IC95\% 1,1 a 3,9). Esto no pudo documentarse en otros períodos del seguimiento. dos (ECCA), con un seguimiento mínimo de 24 semanas, en pacientes con AR que hubieran comparado con placebo $u$ otras drogas modificadoras de la enfermedad (en inglés: DMAR), la eficacia y seguridad de las siguientes drogas: Abatacept, Adalimumab, Anakinra, Certolizumab, Etanercept, Golimumab, Infliximab, Rituximab y Tocilizumab. Los datos fueron extraídos por revisores independientes.

\section{Resultados principales}

Fueron identificadas 16.587 citas bibliográficas, de las cuales 63 ECCA (un total de 29.423 pacientes) reunieron finalmente los criterios de inclusión para la revisión. Los resultados principales se detallan en la tabla 1.

\section{Comentario}

Las terapias biológicas proporcionan una mejoría clínica importante en aquellos pacientes que no responden a las DMAR, reduciendo la inflamación y mejorando el control de los síntomas y el daño estructural. Sin embargo, debido a que estos agentes interfieren con el sistema inmune, existen dudas acerca de su seguridad, especialmente en relación a una mayor predisposición para el desarrollo de infecciones y tumores malignos.

Si bien la mayoría de los estudios observacionales documentaron un incremento en el riesgo de neoplasias malignas (RR 1,1 a 5,0 para el linfoma; 1,1 a 1,5 para las neoplasias de piel no melanoma), este riesgo pudo haber sido sobreestimado, dado que los pacientes que utilizaron drogas anti TNF alfa, ${ }^{1,2}$, podrían pertenecer a un subgrupo con formas más graves de la enfermedad y actividad persistente de la misma. Es bien sabido la relación entre la severidad de la AR con un mayor riesgo de neoplasias.

Esta es la primera síntesis de estudios experimentales que

\section{Conclusiones}

El uso de terapias biológicas en pacientes con AR no se asoció con un aumento clínicamente relevante de la incidencia de malignidad.

Fuente de financiamiento: No hubo esponsoreo aporta mayor calidad de evidencia e incorpora datos sobre terapias biológicas con diferentes mecanismos de acción y cuyos resultados son alentadores. Sin embargo, los ECCA tienen la desventaja de un corto tiempo de seguimiento y no reflejan la aparición de los eventos adversos raros. Por lo tanto, consideramos que los estudios observacionales, con tiempos prolongados de seguimiento, siguen siendo una opción adecuada para pesquisar los datos de seguridad (en este caso desarrollo de malignidad).

\section{Conclusiones de los comentadores}

A pesar de las discrepancias en la interpretación de los datos de seguridad publicados, globalmente podemos decir que por ahora las terapias biológicas no parecen estar asociadas a un mayor riesgo de desarrollo de malignidad en pacientes con AR durante el tiempo de seguimiento evaluado.

Ver glosario*

Erika Catay y Javier Rosa [ Sección Reumatología, Servicio de Clínica Médica del Hospital Italiano de Buenos Aires erika.catay@hospitalitaliano.org.ar ]

Catay E y Rosa J. Bajo riesgo de malignidad en pacientes con artritis reumatoidea tratados con terapia biológica. Evid Act Pract Ambul Oct-Dic 2013; 16(4):136. Comentado de: Lopez-Olivo M y col. Risk of Malignancies in Patients with Rheumatoid Arthritis Treated with Biologic Therapy: a meta-analysis. JAMA. 2012;308(9):898-908. PMID: 22948700.

Referencias

1. Bongartz Ty col. Anti-TNF antibody therapy in rheumatoid arthritis and the risk of serious infections and malignancies. JAMA. 2006;295(19):2275-2285.

2. Leombruno $\mathrm{J} \mathrm{y}$ col. The safety of anti-tumour necrosis factor treatments in rheumatoid arthritis. Ann Rheum Dis. 2009;68(7):1136-1145. 